\title{
Experimental Study of Water Film Flow on Large Vertical and Inclined Flat Plate
}

\author{
Y.Q. Yu ${ }^{\mathrm{a}, \mathrm{c}+}, \mathrm{X}$. Cheng ${ }^{\mathrm{a}, \mathrm{b}}$ \\ ${ }^{a}$ School of Nuclear Science and Engineering,Shanghai Jiao TongUniversity, Shanghai 200240,China \\ ${ }^{b}$ Institute for Nuclear and Energy Technologies Research Center Karlsruhe, Karlsruhe 76021, Germany \\ ${ }^{c}$ Nuclear Engineering Division, Argonne National labortary, Lemont, IL 60439, United State
}

\begin{abstract}
Free falling water film flow is widely applied in many industrial fields, including the PCCS (Passive Containment Cooling System) of the Generation III nuclear power plant. This paper describes an experimental study of free falling water film flow on a vertical and an inclined flat plate $(2 \times 5 \mathrm{~m}$ and $0.4 \times 5 \mathrm{~m})$. A capacitance probe and high-speed camera were used to capture the characteristics of film flow with different Reynolds (50 3600). Many statistical variables of the film flow are presented, such as film thickness, wave length, wave frequency, and wave velocity etc. The test data are also compared with Nusselt theory and some empirical correlations from other researches. The effect of Reynolds number and inclination of the plate on film flow are studied.

Three transition points which indicate different flow mechanism changes are found by analyzing different statistical film flow variables. With the increase of Reynolds number, the solitary waves of film flow develop from low speed waves of high frequency and short wave length to high speed waves of low frequency and long wave length. Empirical correlations of $\bar{\delta}, \delta_{\min }, \delta_{\max }, \delta_{\text {sub }}, \delta_{\mathrm{p}}, \mathrm{U}_{\text {wave }}$ of film flow on large flat plate are obtained. It could be applied to the safety analysis program for PCCS.
\end{abstract}

Keywords: PCCS; water film; flat plate; solitary wave; inclined plate.

\section{Introduction}

Free film flow has been widely applied in industrial fields and investigated for decades due to the high thermal efficiency. Nusselt (1916) proposed a laminar model for film flow. The model assumes that the film flow is laminar with smooth surface and the shear stress on liquid-gas interface is neglected. A parabolic velocity distribution inside film flow can be obtained by solving Navier-Stokes equations for film flow

$$
U_{z}(y)=\frac{\rho g \delta^{2}}{2 \mu}\left[\frac{2 y}{\delta}-\left(\frac{y}{\delta}\right)^{2}\right]
$$

Based on the principle of mass conservation, velocity distribution and definition of Reynolds number of film flow (equation 2), the relationship between film thickness and Reynolds number can be obtained in equation

* Corresponding author. Tel.: +1-630-252-1604.

E-mail address: yyu@anl.gov. 
3.

$$
\begin{gathered}
\operatorname{Re}=\frac{4 \Gamma}{\mu} \\
\delta=\left(\frac{3}{4}\right)^{1 / 3} \operatorname{Re}^{1 / 3}\left(\frac{v^{2}}{g}\right)^{1 / 3}
\end{gathered}
$$

Where $\Gamma$ is the linear mass velocity $(\mathrm{kg} / \mathrm{m} \cdot \mathrm{s})$, Re is Reynolds number and $\mathrm{v}$ is dynamic viscosity of film flow $\left(\mathrm{m}^{2} / \mathrm{s}\right)$. The disadvantage of Nusselt theory is its smooth surface assumption. The instability is one of the most significant characteristic of film flow, which leads to the production of surface wave. When film is falling down, it is influenced by small disturbances which will gradually develop to big solitary waves. The fluid in substrate is laminar while the fluid in solitary wave can be turbulent. Most theoretical studies are based on smooth surface assumption, the fidelity of which is poor.

In the PCCS (Passive Containment Cooling System) of the Generation III nuclear power plant AP1000, the water from a storage tank is driven by gravity and forms a film over the containment during accidents. Film flow on the containment plays the role of final heat sink. Due to large diameter of the containment, film flow on a slice of the containment can be considered as film flow on a large flat plate. Figure 1 presents some parameters of film flow experiments on flat plates. Telles and Dukler (1970) tried to portray the wave characteristic of film flow with a statistical approach. Nosoko et al., (1996) and Yoshimura et al., (1996) observed temporal and spatial flow patterns of a falling film on a flat plate under artificial disturbances. The relationship between the film velocity, wave amplitude, wave length, fluid property and Reynolds number of film flow were obtained. These researches also proposed a double boundary layer model to explain the enhancement of mass transfer due to surface waves in laminar film flow. Takamasa and Hazuku (2000) applied LFD (Laser Focus Displacement meter) to study the effect of Reynolds number and the plate length on film flow behavior. They believed that film flow remains laminar when the Reynolds number is less than 500 . Philipp and Ulrich (2000) observed the wave morphology of film flow. They found remarkable changes of flow behavior and wave structure when the Reynolds number of film flow is close to some transition point. Moran et al., (2002) measured the thickness, velocity distribution and wall shear stress of film flow on an inclined plate. Their results showed that the Nusselt theory underestimates the film thickness and overstates the film velocity. The study also suggested that film fluid is not in a steady state of uniform motion but in a semi steady state of continuous acceleration and deceleration. Ambrosini et al., (2002) studied the statistical characteristics of film flow with different temperature, plate inclination, and Reynolds number. Tihon et al., (2006) found that wave length and height of a solitary wave are proportional to Reynolds number and inversely proportional to enforced disturbance frequency. A linear relationship between wave velocity and maximum film thickness was found. Non-Newtonian liquid spreading on an inclined plate was studied experimentally and numerically by Sutalo et al., (2006). The film shape, width and time dependent velocity profiles were reported. Xu (2010) observed the characteristics of surface waves and film breakup on flat plates. Brissinger D., et al., (2014) use optical method to study films with average thicknesses between 100 and $380 \mu \mathrm{m}$ on a vertical $2 \mathrm{~m}$ high and $1 \mathrm{~m}$ wide wall. The observations showed that the water flow velocity decreases until the film is broken into streams, no longer covering the plate as a continuous film. For both thickest thicknesses, a near-Gaussian shaped distribution is obtained. Gonda A et al., (2014) presented experimental results of both hydrodynamic and thermal tests on the study of falling water film evaporation on a single vertical corrugated stainless steel plate. Study of the falling film hydrodynamics has shown that the decreasing film flow-rate mode could ensure a good wetting of the plate surface area, even at low flow-rates. However, this is not the case for increasing film flow-rate. Wang T., et al., (1994) conducted film flow experiments in a $1.2 \mathrm{~m} \times 1.2 \mathrm{~m} \times 1.7 \mathrm{~m}$ high chamber with Perspex walls. Flow patterns created by liquid jets impinging at angles off horizontal were studied. The falling film exhibited three forms of behavior: a wide film, termed gravity flow; a narrowing film, termed rivulet flow, and a wide film which split into two with the 
formation of a dry patch. The transition to form a dry patch was found to obey the minimum wetting rate criterion.

It can be seen that film flow has been extensively studied for several decades. However, the hydrodynamics of thin film flow are not yet fully understood. Moreover, most experimental studies focused on free film flow on plates of small scale. Only modest attention has been devoted to film flow on large plates. It is hard to fully reflect the hydrodynamics of film flow behavior on the containment (Takahama and Kato 1980) with the experiments on small plate (the containment diameter is over $40 \mathrm{~m}$ while the containment height is over $80 \mathrm{~m}$ ). In order to achieve a better understanding of flow mechanisms on film flow on large plate, which is helpful for evaluating and improving the PCCS, this paper describes an experimental study of falling film flow on a vertical and an inclined plate of large scale with wide range of Reynolds number. The empirical correlations obtained in this study can be applied to the safety analysis programs for nuclear power plant, such as GASFLOW and WGOTHIC. In these programs, theoretical correlations are usually used to study the hydraulic characteristics of film flow. The reliable correlations of film flow on large flat plate can be beneficial for improving the precision of solutions. The instability analysis is not included in this paper, but it is suggested in future works based on energy gradient method and Semi-analytical method. ( Hajmohammadi and Nourazar (2014 a, b, c).

Table1. Film Flow Experiment on Flat Plate

\begin{tabular}{|c|c|c|c|c|c|}
\hline Researcher & $\begin{array}{l}\text { Experimental area } \\
\text { Width X Length } \\
(\mathrm{cm})\end{array}$ & $\begin{array}{c}\text { Plate } \\
\text { Material }\end{array}$ & $\begin{array}{l}\text { Inclination } \\
\text { Angle }\end{array}$ & $\begin{array}{c}\text { Range of } \\
\text { Reynolds } \\
\text { number }\end{array}$ & Measured Parameters \\
\hline $\begin{array}{l}\text { Takamasa and } \\
\text { Hazuku } \\
(2000)\end{array}$ & $22 \times 46$ & Plastic & $90^{\circ}$ & $128 \sim 2824$ & $\begin{array}{l}\text { film thickness, film velocity, volume } \\
\text { flow rate }\end{array}$ \\
\hline $\begin{array}{l}\text { Nosoko et al., } \\
\text { (1996) } \\
\text { Yoshimura et al., } \\
\text { (1996) }\end{array}$ & $\begin{array}{c}20.5 \times 24.5 \\
20.5 \times 49\end{array}$ & Glass & $90^{\circ}$ & $40 \sim 400$ & $\begin{array}{l}\text { film temperature, volume flow rate, } \\
\text { wave morphology, wave frequency, } \\
\text { wave length }\end{array}$ \\
\hline $\begin{array}{l}\text { Philipp and Ulrich } \\
\text { (2000) }\end{array}$ & $3 \times 20$ & Glass & $90^{\circ}$ & $108 \sim 800$ & $\begin{array}{l}\text { film thickness, film velocity, volume } \\
\text { flow rate }\end{array}$ \\
\hline $\begin{array}{l}\text { Sutalo et al., } \\
\text { (2006) }\end{array}$ & $5 \times 38.1$ & Plastic & $45^{\circ}$ & $12 \sim 52$ & $\begin{array}{l}\text { film thickness, film morphology, } \\
\text { volume flow rate }\end{array}$ \\
\hline $\begin{array}{l}\text { Moran et al., } \\
\quad(2002)\end{array}$ & $8 \times 192$ & Copper & $45^{\mathrm{O}}$ & $11 \sim 220$ & $\begin{array}{l}\text { film thickness, film velocity, volume } \\
\text { flow rate }\end{array}$ \\
\hline Xu (2010) & $5 \times 8$ & $\begin{array}{l}\text { Stainless } \\
\text { Steel }\end{array}$ & $60^{\circ}$ & $50 \sim 300$ & $\begin{array}{l}\text { film thickness, film velocity, volume } \\
\text { flow rate }\end{array}$ \\
\hline $\begin{array}{l}\text { Tihon et al., } \\
\text { (2006) }\end{array}$ & $22 \times 200$ & $\begin{array}{l}\text { Stainless } \\
\text { Steel }\end{array}$ & $5^{\mathrm{O}}$ & $40 \sim 400$ & $\begin{array}{l}\text { film thickness, wall shear stress, volume } \\
\text { flow rate }\end{array}$ \\
\hline $\begin{array}{l}\text { Ambrosini et al., } \\
\text { (2002) }\end{array}$ & $60 \times 200$ & $\begin{array}{l}\text { Stainless } \\
\text { Steel }\end{array}$ & $\begin{array}{l}45^{\mathrm{O}} \\
90^{\mathrm{O}}\end{array}$ & $140 \sim 3200$ & $\begin{array}{l}\text { film temperature, volume flow rate, air } \\
\text { velocity, wall temperature, wave } \\
\text { velocity }\end{array}$ \\
\hline
\end{tabular}

\section{Nomenclature}

Re Reynolds number

$\rho$ is fluid density $\left(\mathrm{kg} / \mathrm{m}^{3}\right)$

$v$ dynamic viscosity $\left(\mathrm{m}^{2} / \mathrm{s}\right)$

$\mu$ molecular viscosity $(\mathrm{Pa} \cdot \mathrm{s})$
$\Gamma$ linear mass velocity $(\mathrm{kg} / \mathrm{m} \cdot \mathrm{s})$

g gravitational acceleration $\left(\mathrm{m} / \mathrm{s}^{2}\right)$

$\mathrm{n}$ number of data

$\delta$ film thickness $(m)$ 
s standard deviation of film thickness $(m)$

$\delta^{\prime}$ growth rate of film thickness $(\mathrm{m} / \mathrm{s})$

$w$ shear stress velocity $(\mathrm{m} / \mathrm{s})$

$\tau_{\mathrm{w}}$ wall shear stress $(\mathrm{Pa})$

PDF Probability Density Function

$f$ wave frequency $(\mathrm{Hz})$

$\mathrm{t}$ time $(s)$

$\sigma$ surface tension $(\mathrm{N} / \mathrm{m})$ $\delta_{\mathrm{p}}$ Height of solitary wave $(m)$

$\delta^{\prime \prime}$ acceleration of film thickness growth $\left(\mathrm{m} / \mathrm{s}^{2}\right)$

$\tau_{\mathrm{c}}$ characteristic shear stress $(\mathrm{Pa})$

$\tau_{\mathrm{i}}$ interfacial wall shear stress $(P a)$

U velocity $(\mathrm{m} / \mathrm{s})$

$\lambda$ wave length $(m)$

$\phi$ angle between plate and horizontal direction $\gamma$ Kapitza number

max maximum value

wave solitary wave

min minimum value

sub substrate value

film film flow

\section{Superscripts}

- average

+ dimensionless

\section{Experimental Methodology}

\subsection{Description of the Experiment}

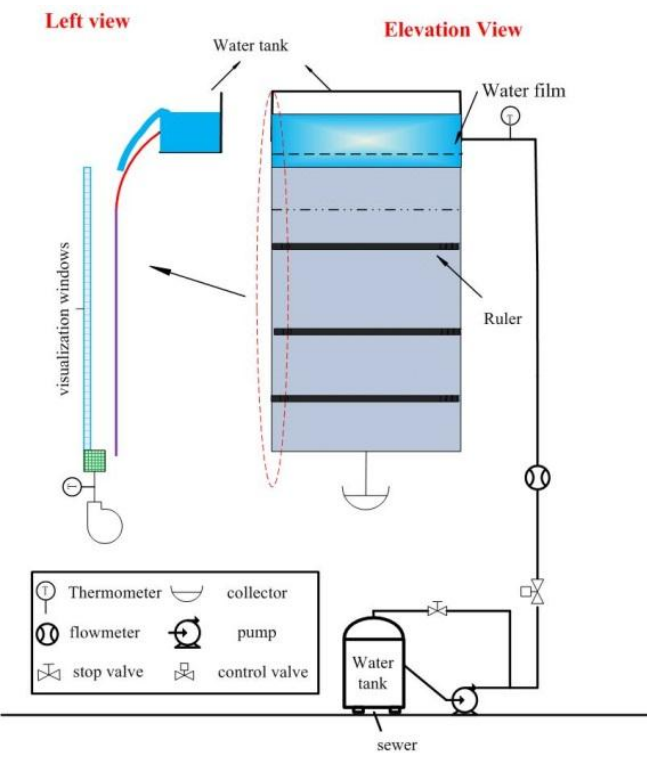

(a) WABREC

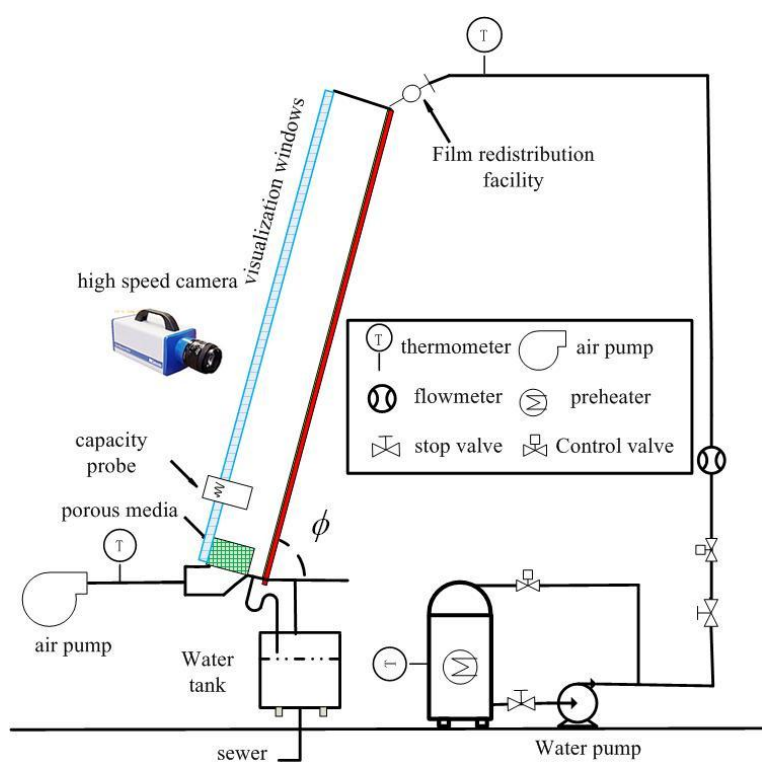

(b) MICARE+

Fig. 1. Sketch of the Two Experimental Test Loops

Two test rigs were used for this study: WABREC (Water Behavior in REctangle Channel), and MICARE+ (MIx Convection Air in REctangle Channel +). The main parameters of these test loops are listed in Table 2. It is worth mentioning that MICARE+ is a modified version of the air convection test loop MICARE (Qiu et al., 2009), altered for film flow study. These two test loops focus on different aspects of film flow study. WABREC was built for film breakup study because the plate of WABREC is wide enough to eliminate the 
edge effect. MICARE+ was built for studying the film flow with counter current air action because it is more practicable to produce uniform counter current air flow into a narrower channel. We are presenting some part of the data from the two experiments together because they demonstrate the feature of free falling continuous film flow. The sketches of the test loops are shown in figure 1.WABREC and MICARE+ share the same water circulation system and flow control system. Both test plates are made of stainless steels and coated with Carbozinc $11 \mathrm{HSN}$, the same coating used for the containment of AP1000. It is worth mentioning that the test plate is not heated. There are visualization windows which are made of Plexiglas $0.2 \mathrm{~m}$ in front of the plate. Water is pumped from a storage tank to a distribution tank on top of the experimental section, where it then flows down the plate to a collection tank and drains. The two key instruments are a capacitance probe and high-speed camera, which is responsible for capturing the film thickness and the morphology of solitary waves. The measuring frequency of the capacity probe is $1000 \mathrm{~Hz}$ and the camera frame rate is $1000 \mathrm{fps}$. According to the calibration, the measurement error of the capacitance probe is $5 \%$ within its measuring range. The working fluid is water at ambient temperature and pressure. More detailed information about the experimental rig and results has been reported in Yu Y.Q., Wei S.J., et al., (2012), Yu Y.Q., Yang Y.H., et al., (2012), Yu et al., (2013).

Table 2: Paramters of WABREC and MICARE+

\begin{tabular}{cccccc}
\hline Parameters & $\begin{array}{c}\text { Width } \\
(\mathrm{m})\end{array}$ & $\begin{array}{c}\text { Length } \\
(\mathrm{m})\end{array}$ & $\begin{array}{c}\text { Height } \\
(\mathrm{m})\end{array}$ & $\begin{array}{c}\text { Reynolds number } \\
\text { range }\end{array}$ & $\begin{array}{c}\text { Inclination } \\
\text { range }\end{array}$ \\
\hline WABRaratus & 2 & 5 & 0.2 & $50 \sim 900$ & $90^{\circ}$ \\
MICARE+ & 0.4 & 5 & 0.2 & $200 \sim 3600$ & $30 \sim 80^{\circ}$ \\
\hline
\end{tabular}

The method used to measure the wave velocity with the high-speed camera is shown in figure 2 . Two parallel lines were marked in advance in the measuring area. The distance between them is d. The solitary wave moves from position (a) to position (b) over a period of time $(\Delta \mathrm{t})$. The average wave velocity is calculated as follows:

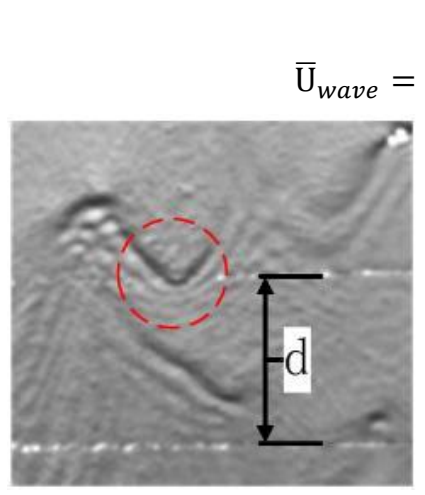

(a)

Fig. 2. Measurement method of velocity of surface wave 


\subsection{Data Definition and Parameterization}

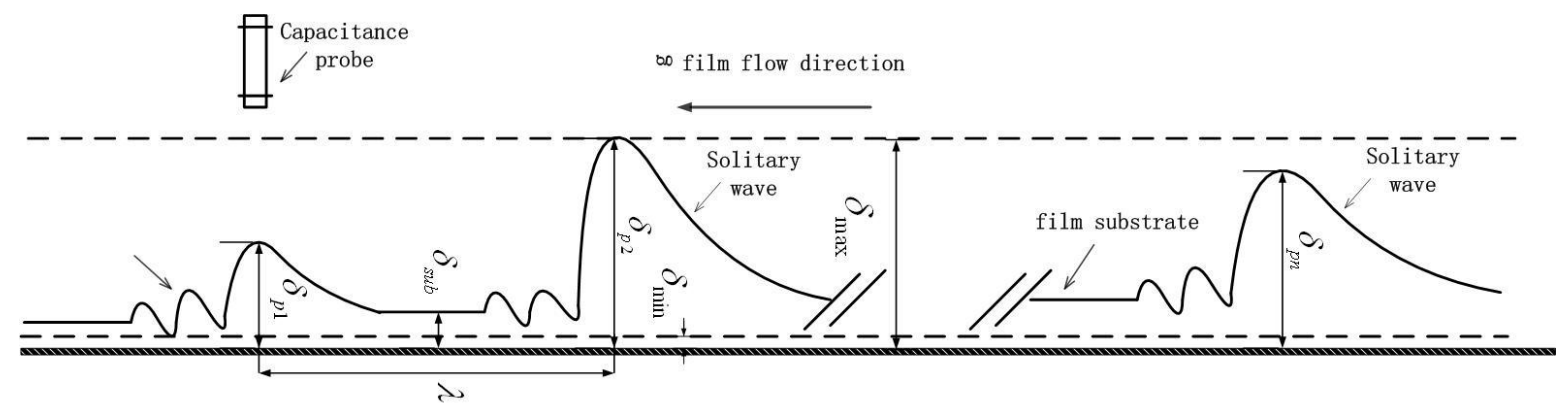

Fig. 3. Sketch of film flow structure

As shown in figure 3, free falling film flow usually consists of film substrates, large solitary waves, and small capillary waves in front of solitary waves. As a result of the chaotic characteristic of film flow (Chang 1987), film flow behavior is very random. Therefore, it is reasonable to describe the film flow behavior statistically. However, large amounts of data are necessary for such descriptions. For instance, 30 seconds measurement of film thickness leads to $6 \times 10^{5}$ test data for whole Reynolds number range. Thus one of the topics of this paper is how to extract meaningful information from these data.

For clarity, these statistical variables are divided into two groups:

- Statistical variables of film thickness: average film thickness, maximum film thickness, minimum film thickness, standard deviation of film thickness, etc.

- Statistical variables of surface wave: wave frequency, wave length, wave velocity, etc.

Average film thickness $(\bar{\delta})$ :

$$
\bar{\delta}=\frac{\sum_{i=1}^{n} \delta_{i}}{n}
$$

Maximum and minimum film thickness is denoted as $\delta_{\max }$ and $\delta_{\min }$ respectively.

Standard deviation of film thickness:

The Probability Density Function (PDF) of film:

$$
\mathrm{s}=\sqrt{\frac{\sum_{i=1}^{n}\left(\delta_{i}-\bar{\delta}\right)^{2}}{n-1}}
$$

$$
\begin{gathered}
F(\delta)=\frac{N u m_{i=1}^{n}\left(\delta_{i}<\delta\right)}{n} \\
P D F(\delta)=\frac{d F(\delta)}{d \delta}
\end{gathered}
$$

where $F(\delta)$ is the probability distribution function and $\operatorname{Num}_{i=1}^{n}\left(\delta_{i}<\delta\right)$ represents number of the test data when the test data is less than $\delta$.

Substrate thickness $\left(\delta_{\text {sub }}\right)$ defines the thickness of the laminar film flow betweem solitary waves. This paper

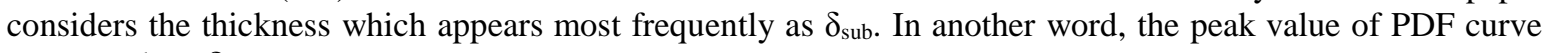
coresponds to $\delta_{\text {sub. }}$

Average wave height $\left(\overline{\delta_{p}}\right)$ :

$$
\overline{\delta_{p}}=\frac{\sum_{i=1}^{n} \delta_{p i}}{n}
$$

Growth rate of film thickness $\left(\delta^{\prime}\right)$ defines the film surface velocity in the film thickness direction:

$$
\delta^{\prime}=\mathrm{d} \delta / \mathrm{dt} \cong \lim _{\Delta t \rightarrow 0} \frac{\Delta \delta}{\Delta t}=\frac{1}{\Delta t}\left[\delta\left(t+\frac{\Delta t}{2}\right)-\delta\left(t-\frac{\Delta t}{2}\right)\right]
$$


Acceleration of film thickness growth $\left(\delta^{\prime \prime}\right)$ defines the film surface acceleration in the film thickness direction:

$$
\delta^{\prime \prime}=\frac{\mathrm{d}^{2} \delta}{\mathrm{dt}^{2}} \cong \frac{1}{\Delta t}\left[\left(\frac{\Delta \delta}{\Delta t}\right)_{\left(t+\frac{\Delta t}{2}\right)}-\left(\frac{\Delta \delta}{\Delta t}\right)_{\left(t-\frac{\Delta t}{2}\right)}\right]=\frac{1}{\Delta t^{2}}[\delta(t+\Delta t)-2 \delta(t)+\delta(t-\Delta t)]
$$

Wave velocity $\left(\mathrm{U}_{\text {wave }}\right)$ is the velocity of a solitary wave in film flow direction.

Wave length $(\lambda)$ is the distance between solitary waves.

where $f$ is wave frequency.

$$
\lambda=\frac{U_{\text {wave }}}{f}
$$

\section{Results and Discussion}

\subsection{Statistical Characteristics of Film Thickness}

Early results on statistical characteristics of film thickness in WABREC, reported in Yu et.al., (2012), indicated two transition points within the studied Reynolds number range. We believed that it is due to the transition of the wave pattern. A better understanding of these transition points may be obtained by presenting maximum film thickness in a different dimensionless form. (Figure 4).

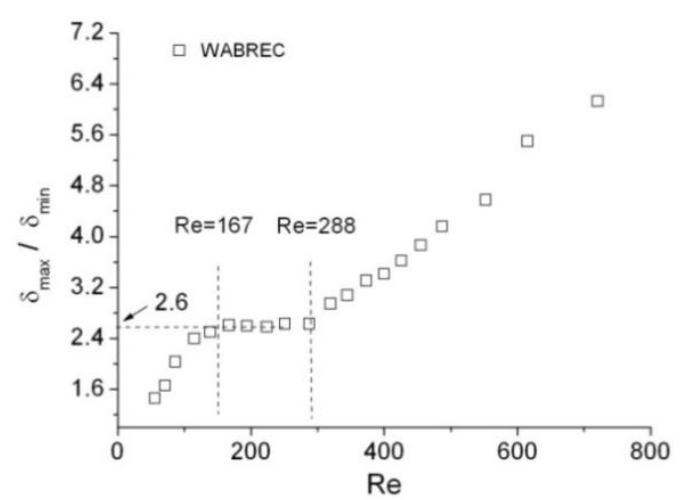

(a) $\delta_{\max } / \delta_{\min }$ vs $\operatorname{Re}$

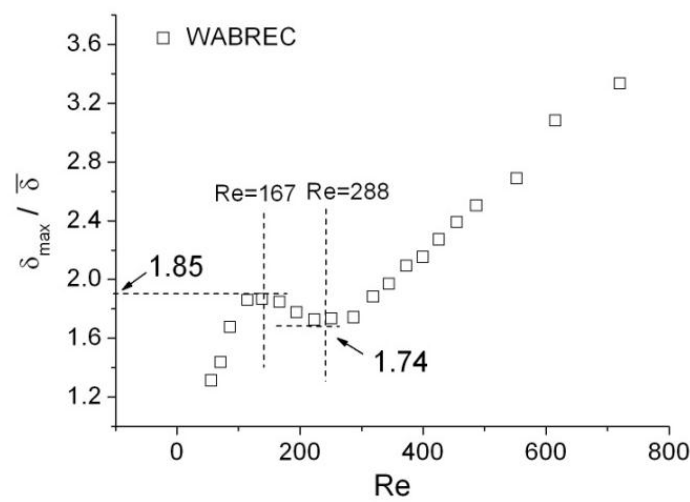

(b) $\delta_{\max } / \bar{\delta}$ vs $\operatorname{Re}$

Fig. 4. Dimensionless maximum film thickness as a function of Reynolds number

Two obvious transition points of film flow in WABREC appear at Reynolds number of 167 and 288. $\delta_{\max } /$ $\delta_{\min }$ keeps constant at 2.6 between these two transition points. From previous report (Yu Y.Q., Wei S.J., (2012)), $\delta_{\min }$ hardly changes with increase of Reynolds number, which means that $\delta_{\max }$ is also nearly constant between the two transition points. $\delta_{\max } / \bar{\delta}$ reaches 1.85 at first transition point, which agrees with Karapantsios's et al., (1995) study. The increase of $\delta_{\max } / \bar{\delta}$ after the second transition point indicates the appearance of "heap waves" which carry huge amount of mass and energy. An explanation of "heap waves" can be found in Yu Y.Q., Wei S.J., et.al., (2012). Based on the analysis above, two transition points reveal the threshold of some changes. The first one indicates that the self-lock of solitary waves' structure occurs. The increment of flow flux only leads to the rise of wave frequency. The analysis on the wave frequency in section 3.2 proves this view. The second one indicates that the heap waves begin to appear. 


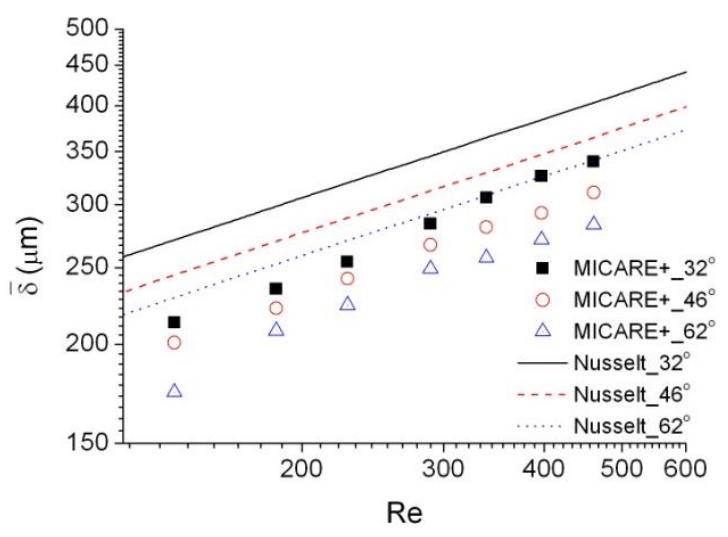

(a) Average film thickness at different inclination

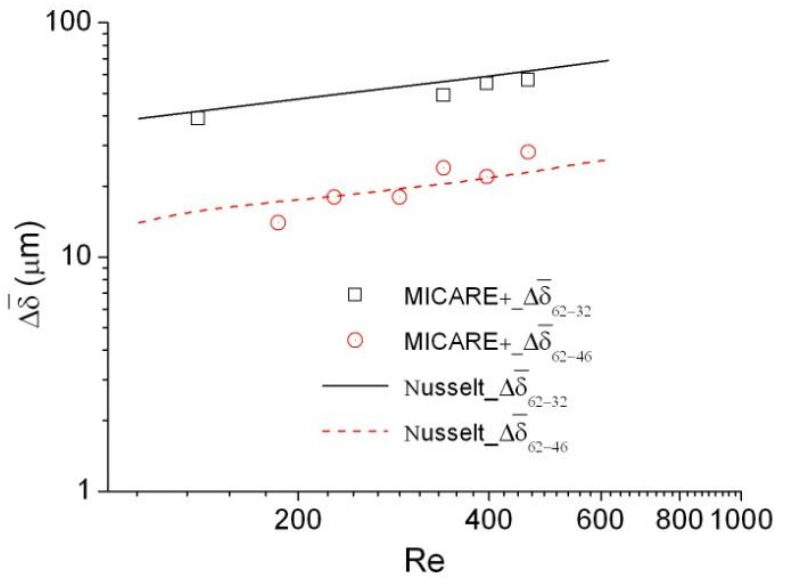

(b) Average film thickness difference

Fig. 5. Average film thickness in MICARE+

The angle $\varnothing$ between the test plate of MICARE+ and horizontal direction is kept $32^{\circ}, 46^{\circ}$ and $62^{\circ}$ respectively to study the effect of the plate inclination on film flow. Figure 5 shows the average film thickness with different plate inclinations. Good linear relationships are found between the average film thickness and Reynolds number under logarithmic coordinates. The film velocity is increased with the inclination, which results in a decrease of the average film thickness. Nusselt theory overestimates the film thickness due to its idealized assumptions. However, the difference value of film thickness with difference inclinations agrees well the value calculated with Nusselt theory. According to the equation 13, the difference value of film thickness from Nusselt theory is obtained:

$$
\Delta \bar{\delta}=C R e^{1 / 3}\left(\left(\sin \emptyset_{1}\right)^{-1 / 3}-\left(\sin \emptyset_{2}\right)^{-1 / 3}\right)
$$

Where $\mathrm{C}$ is a constant related to fluid property and local gravity. $\Delta \bar{\delta}_{\emptyset_{1}-\emptyset_{2}}$ in figure $5 \mathrm{~b}$ represents the difference value of film thickness between test data with plate inclination $\emptyset_{1}$ and $\emptyset_{2}$.

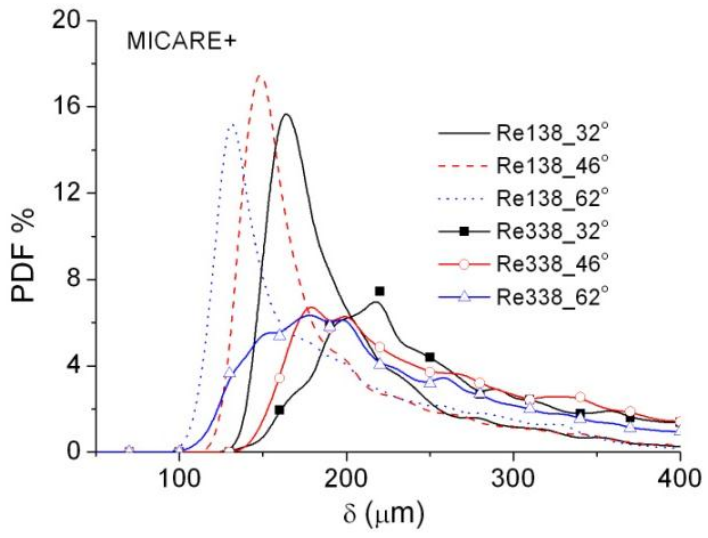

(a)PDF

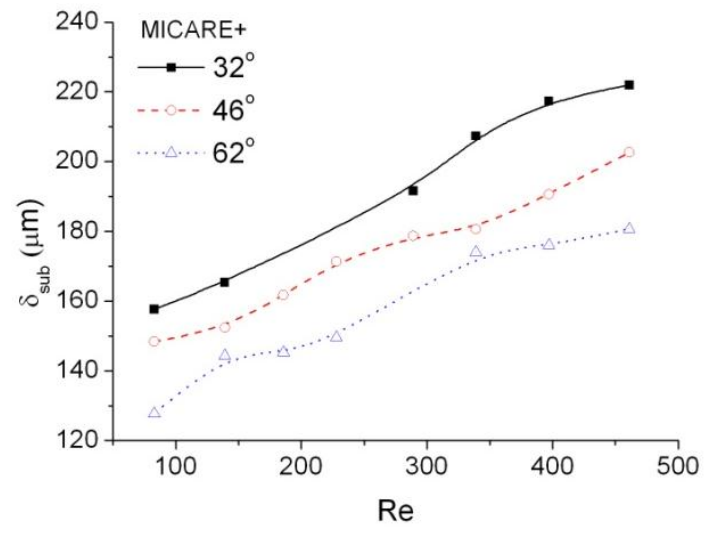

(b) $\delta_{\text {sub }}$

Fig. 6. Probability density function and $\delta_{\text {sub }}$ of film thickness in MICARE+ 
Figure 6 shows the Probability Density Function (PDF) and $\delta_{\text {sub }}$ in MICARE+. The position of the peak value on PDF curves changes with the plate inclination, which suggests that the variation of film substrate thickness. $\delta_{\text {sub }}$ decreases with increase of the inclination due to acceleration of the film flow.

\subsection{Statistical Characteristics of Solitary Wave}

Although there is no net flow in film thickness direction, surface of film flow moves along this direction periodically and intensively. Growth rate of film thickness $\left(\delta^{\prime}\right)$ and acceleration of film thickness growth $\left(\delta^{\prime \prime}\right)$ can characterize this movement. Figure 7 shows how these variables behave during the growth of a typical solitary wave. Like a simple harmonic vibration, the film surface moves from the crest to the valley again and again with accelerations and deceleration. When the film surface reaches the valley or the crest of solitary wave, $\delta^{\prime}$ is almost 0 , while $\delta^{\prime \prime}$ reaches the maximum value.

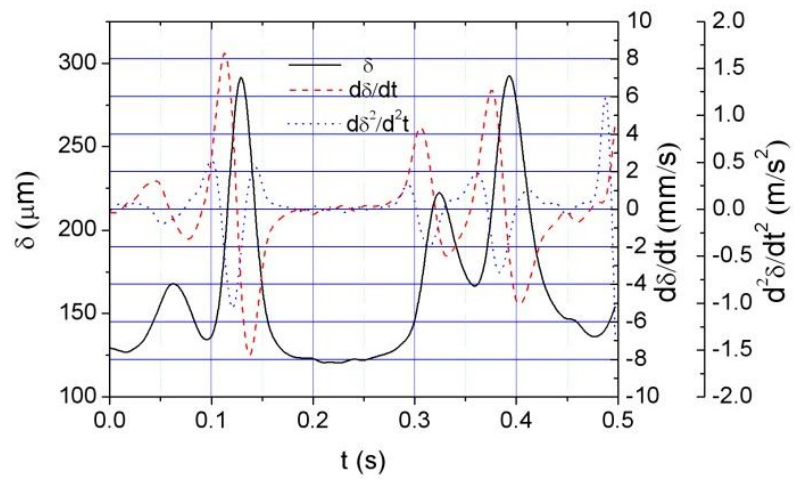

Fig. 7. Instantaneous $\delta, \delta^{\prime}$ and $\delta^{\prime \prime}$

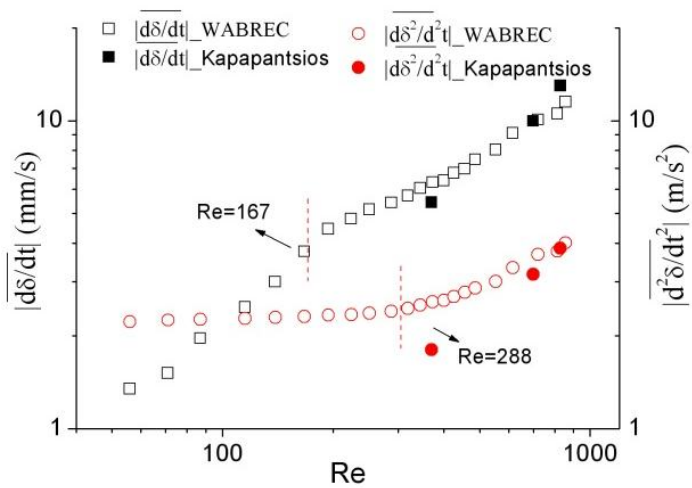

(a) $\left|\overline{\delta^{\prime}}\right|$ and $\left|\overline{\delta^{\prime \prime}}\right|$

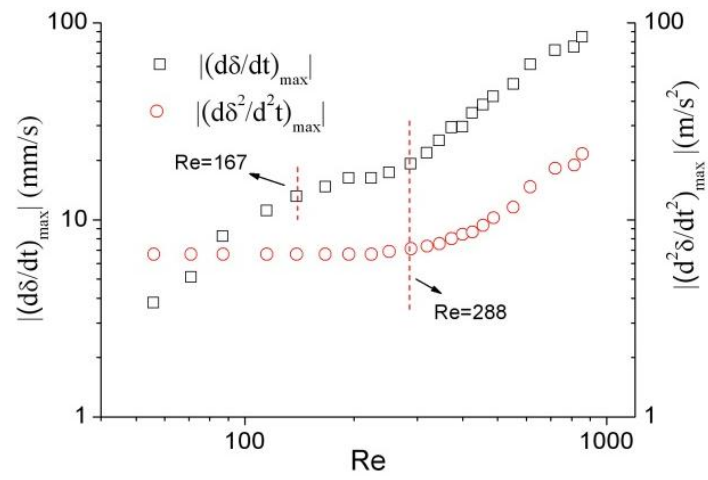

(b) $\left|\delta_{\text {max }}{ }^{\prime}\right|$ and $\left|\delta_{\text {max }}{ }^{\prime \prime}\right|$

Fig. 8. $\left|\overline{\delta^{\prime}}\right|,\left|\overline{\delta^{\prime \prime}}\right|,\left|\delta_{\max }{ }^{\prime}\right|$ and $\left|\delta_{\max }{ }^{\prime \prime}\right|$ in WABREC

The absolute values of time averaged and maximum $\delta^{\prime}$ and $\delta^{\prime \prime}$ in WABREC are shown in Figure 8 . Wave velocity transition points are evident at $\mathrm{Re}=167$ and 288 while an acceleration transition point appears only at 
$\operatorname{Re}=288 .\left|\overline{\delta^{\prime}}\right|$ and $\left|\overline{\delta^{\prime \prime}}\right|$ are approximately $1 \sim 11 \mathrm{~mm} / \mathrm{s}$ and $2 \sim 4 \mathrm{~m} / \mathrm{s}^{2}$ repectively, which agree well with the test reults from Karapantsios's and Karabelas (1995) research.

Average wave height $\overline{\delta_{p}}$ characterizes the scale of a solitary wave. Figure 9 shows the comparison between $\overline{\delta_{p}}, \bar{\delta}, \overline{\delta_{p}}-\delta_{\text {sub }}, \overline{\delta_{p}}-\bar{\delta}$ as well as Ito's (1986) empirical correlation of $\overline{\delta_{p}}$ over Reynolds number, which is listed as follows:

$$
\bar{\delta}_{p_{-} I t o}=0.46 R e^{0.53}\left(\frac{v^{2}}{g}\right)^{1 / 3}
$$

Two transition points are apparent in profiles of $\overline{\delta_{p}}-\delta_{s u b}, \overline{\delta_{p}}-\bar{\delta}$. Ito's (1986) correlation under-predict the $\overline{\delta_{p}} 8 \%$ when Reynolds number is large.

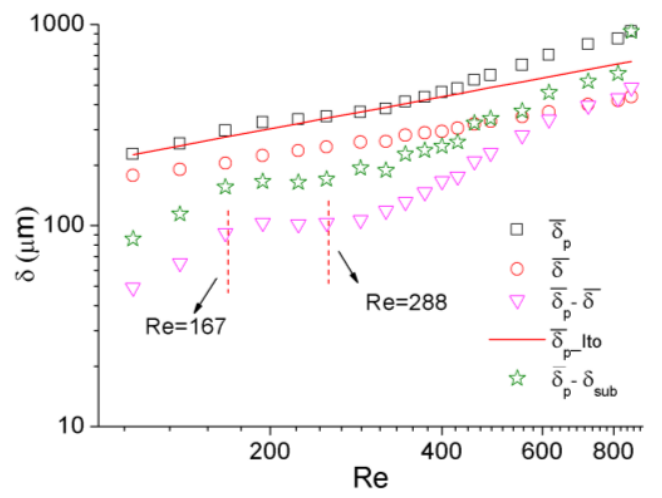

Fig. 9. $\overline{\delta_{p}}, \bar{\delta}, \overline{\delta_{p}}-\delta_{s u b}$ and $\overline{\delta_{p}}-\bar{\delta}$ in WABREC

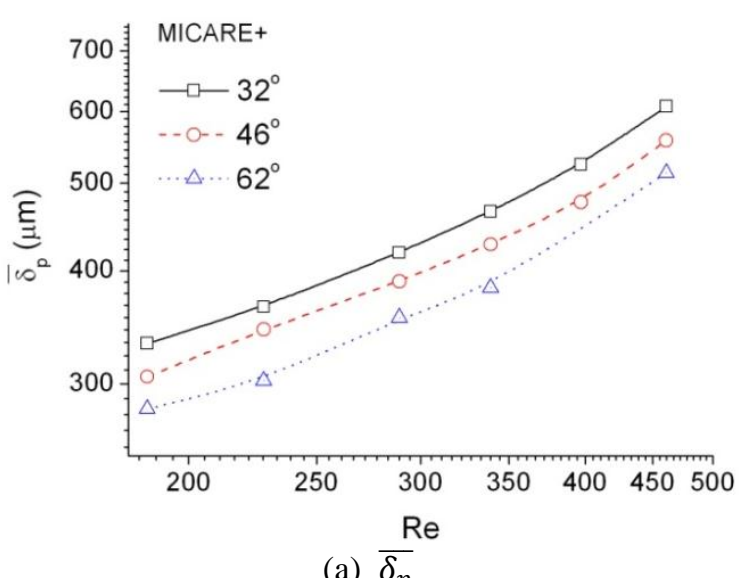

Fig. 10. Effect of the inclination on wave height

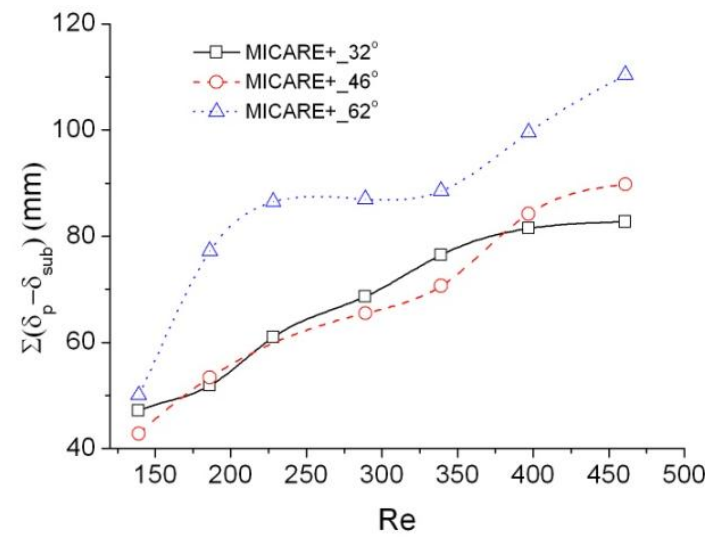

(b) $\sum\left(\delta_{p}-\delta_{\text {sub }}\right)$

The average wave height $\overline{\delta_{p}}$ decreases as the plate inclination is increased (figure10a). However, greater $\overline{\delta_{p}}$ doesn't mean that the surface wave is more violent. Figure10b shows the sum of $\delta_{p}-\delta_{s u b}$ during the measuring time, which indicates how much fluid exists in form of solitary waves. It obvious that $\sum\left(\delta_{p}-\right.$ $\delta_{\text {sub }}$ ) with plate inclination $62^{\circ}$ is much bigger than that with plate inclination $32^{\circ}$ and $46^{\circ}$. It shows that surface wave of the film flow with inclination of $62^{\circ}$ is more violent. Hence, misunderstanding of the film flow behavior can occur if we try to investigate the film flow only from a part of the variables. Therefore, different statistical variables are necessary for fully understanding the film flow characteristics. 


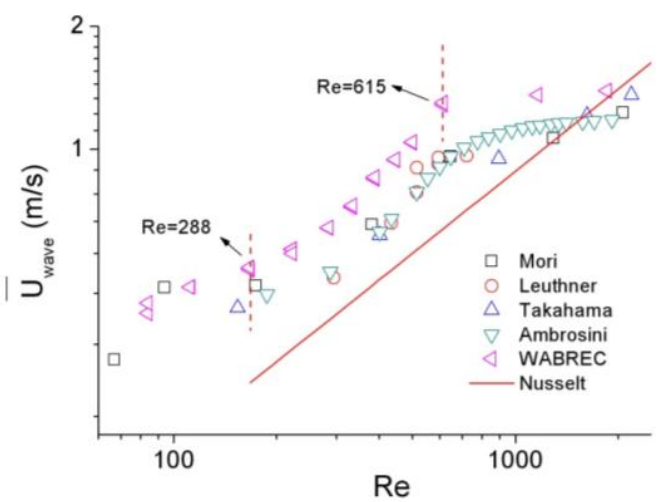

(a) WABREC

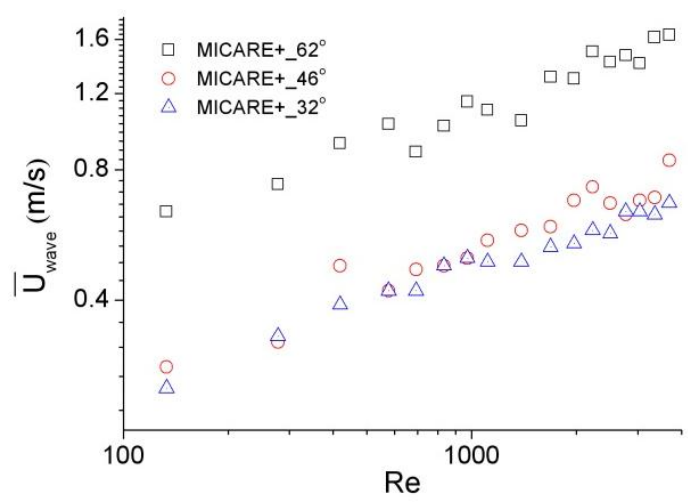

(b) MICARE+

Fig. 11. $\bar{U}_{\text {wave }}$ versus Reynolds number in WABREC and MICARE+

Figure11a compares $U_{\text {wave }}$ in WABREC with the work of (Mori et al., (1998), Leuthner et al., (1988), Takahama et al., (1998), and Ambrosini et al., (2002)). The transition points in WABREC occur at the same Reynolds numbers as the other researches but at higher wave velocity. This is because we have isolated the solitary waves with the high-speed camera while other researchers have used instruments that also include the substrate velocity in their measurements. For instance, Ambrosini et al., (2002) set two capacitance probes in the film flow direction to measure $\bar{U}_{\text {wave }}$ which certainly includes the velocity of the substrate. The data show that $\bar{U}_{\text {wave }}$ becomes nearly constant above a Reynolds number of 615 , which suggests height of the solitary wave becomes steady and the film substrate gradually turns turbulent. Therefore, it is considered as the third transition point, which indicates that the film flow has completely transitioned from laminar flow to turbulent flow.

Figure $11 \mathrm{~b}$ shows the effect of the inclination on $\mathrm{U}_{\text {wave }}$. $\mathrm{U}_{\text {wave }}$ is proportional to Reynolds number under logarithm coordinate with each plate inclination. $U_{\text {wave }}$ with inclination of $62^{\circ}$ is much bigger than the others. We hypothesize that there exist a transition point of the plate inclination. This transition point may indicate that the gravity begins to affect the film flow in different way.

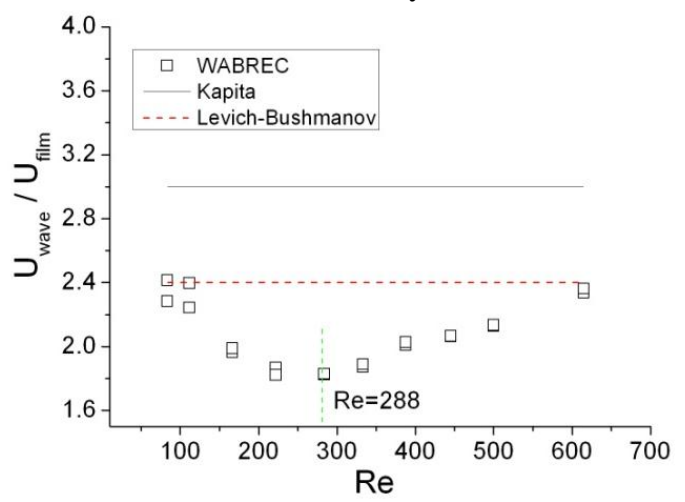

Fig. 12. Dimensionless wave velocity in WABREC

The dimensionless treatement of $U_{\text {wave }}$ with $U_{\text {film }}$ is calculated with the equation 15 and shown in figure 12 with some theoretical values from other research. 


$$
U_{\text {film }}=\frac{\Gamma}{\rho \delta}
$$

The $U_{\text {wave }} / \mathrm{U}_{\text {film }}$ data from this study ranges from 1.8 to 2.4 , while the thereotical value of Kapita (1964) is 3 and Levich-Bushmanov (1962) is 2.4. $\mathrm{U}_{\text {wave }} / \mathrm{U}_{\text {film }}$ tends to increase after some decreases over Reynolds number. We believe it will decrease again after the film flow turn turbulent. (This has been observed from the experimental data of MICARE+ with wider range of Reynolds number.)

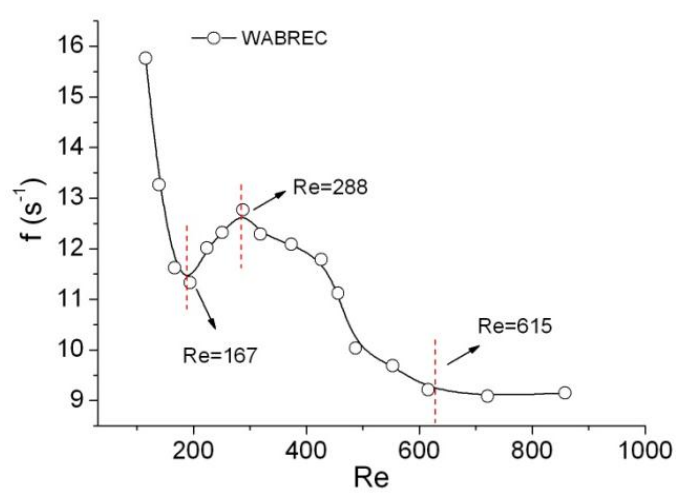

(a) wave frequency

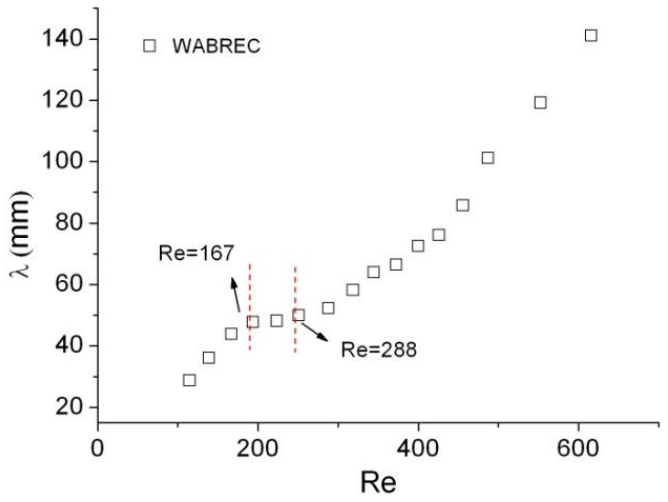

(b) wave length

Fig. 13. Wave frequency and length versus in WABREC

The wave frequency and length (figure 13) reveal some mechanisms of film flow. The wave frequency is divided by transition points into some obvious stages. At first, the Reynolds number is small while the film is thin and unsteady. Many tiny disturbances develop into high frequency surface wave. With an increase of Reynolds number, film flow becomes steady and a majority of disturbances are filtered by surface waves, which lead to a decrease of wave frequency. Between the first and second transition points, the wave pattern, wave height and wave length are brought into self-locking status, which means these parameters almost remain constant. Therefore, the increment of the flow flux directly results in growth of the wave frequency. After the second transition point, the heap waves that carry large amounts of mass and energy appear and merge with small, high frequency solitary waves. It results in the decrease of wave frequency. As the Reynolds number is increased further, the solitary waves of film flow will develop from low speed waves of high frequency and short wave length to high speed waves of low frequency and long wave length. After the third transition point, the changes of these parameters become less notable. The frequency and wave length of film flow in MICARE+ show similar behavior.

\subsection{Empirical Correlations}

Nusselt theory is significant and extensively used not only because it provides us an equation to estimate the film thickness but also a basic form to interoperate the relationship between film thickness and Reynolds number:

$$
\delta=a R e^{b}\left(\frac{v^{2}}{g \sin \varnothing}\right)^{\frac{1}{3}}
$$

where $\mathrm{a}$ and $\mathrm{b}$ are constants, normally fitted to experimental data. However, these constants tend to vary tremendously in different correlations. Our previous analyses indicate that some statistical variables have good linear relationships with Reynolds number under logarithmic coordinate. In order to obtain the empirical 
correlations, it is necessary to process the WABREC and MICARE+ data in a dimensionless form:

$$
\delta^{+}=\frac{\delta w}{v}, \quad w=\sqrt{\frac{\tau_{c}}{\rho}}, \quad \tau_{c}=\frac{2}{3} \tau_{w}+\frac{1}{3} \tau_{i}
$$

Where $v$ is dynamic viscosity $\left(\mathrm{m}^{2} / \mathrm{s}\right), w$ is shear stress velocity $(\mathrm{m} / \mathrm{s}), \tau_{\mathrm{c}}$ is characteristic shear stress $\left(\mathrm{N} / \mathrm{m}^{2}\right), \tau_{\mathrm{w}}$ is wall shear stress $\left(\mathrm{N} / \mathrm{m}^{2}\right), \tau_{\mathrm{i}}$ is interfacial wall shear stress $\left(\mathrm{N} / \mathrm{m}^{2}\right)$, and $\rho$ is fluid density $\left(\mathrm{kg} / \mathrm{m}^{3}\right)$.

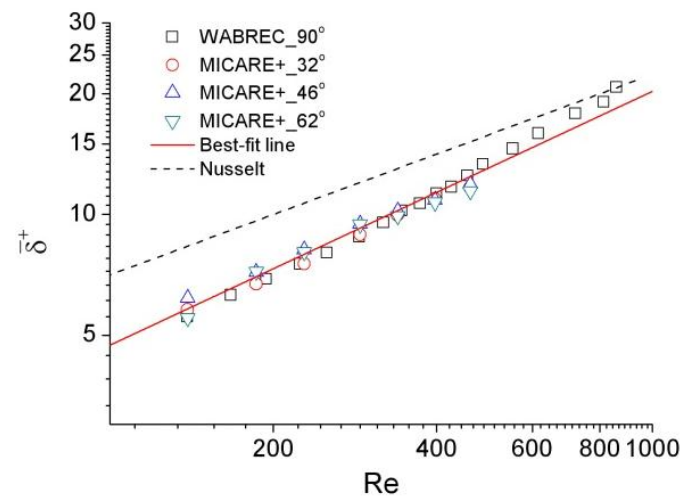

(a) $\bar{\delta}^{+}$

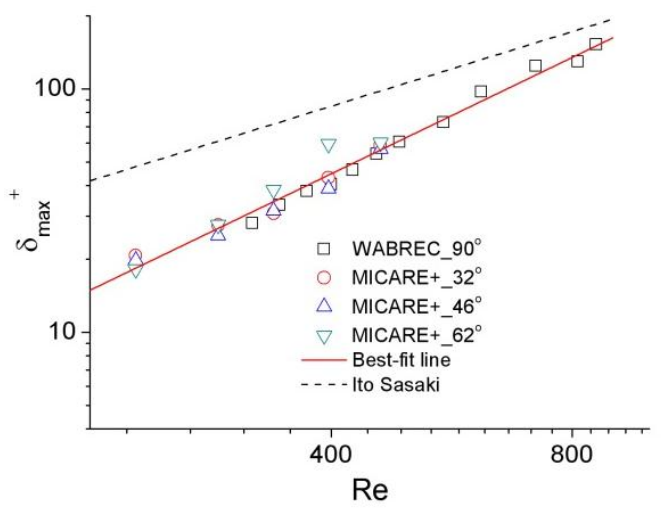

(c) $\delta \max ^{+}$

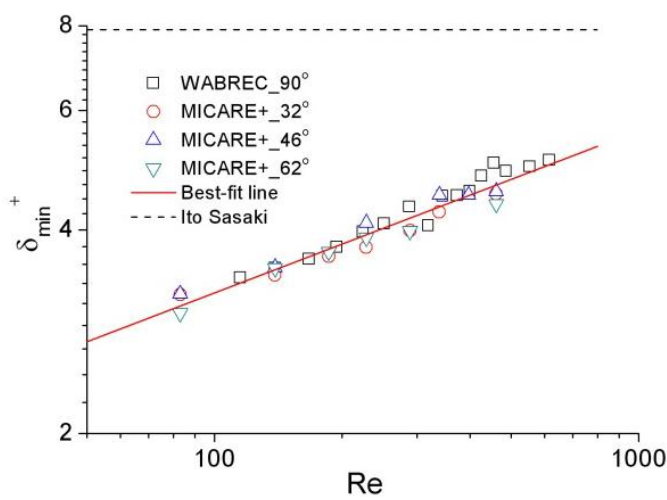

(b) $\delta \min ^{+}$

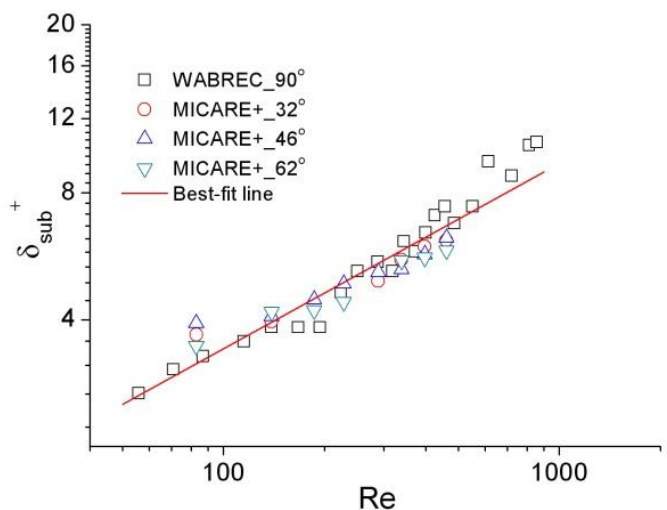

(d) $\delta_{\mathrm{sub}^{+}}$

Fig. 14. Dimensionless statistical parameters of film thickness

The test data of $\bar{\delta}^{+}, \delta \min ^{+}, \delta \max ^{+}$and $\delta \operatorname{sub}^{+}$are presented in figure14. The empirical correlations are obtained from least square fits and the resulting formulus are listed in table $3 . \delta_{\min }{ }^{+}, \delta_{\max ^{+}}$are also compared with Ito’s (1986) empirical correlations:

$$
\begin{gathered}
\delta_{\text {max }}=0.38 R e^{0.68}\left(\frac{v^{2}}{g \sin \varnothing}\right)^{\frac{1}{3}} \\
\delta_{\text {min }}=4.54\left(\frac{v^{2}}{g \sin \varnothing}\right)^{\frac{1}{3}}
\end{gathered}
$$

The comparison between these empirical correlations reveals the significance of the empirical correlations proposed in this paper. It indicates that the statistical variables of film flow on large flat plate is different from 
that of film flow on small tubes or plates.

Table 3 Empirical Correlations for Film Thickness

\begin{tabular}{cccc}
\hline Parameter & Range of Reynolds number & Dimensionless Empirical Correlation & Empirical Correlation \\
\hline $\bar{\delta}$ & $(80<\operatorname{Re}<900)$ & $\bar{\delta}^{+}=0.256 R e^{0.633}$ & $\bar{\delta}=0.462 R e^{0.422}\left(\frac{v^{2}}{g \sin \varnothing}\right)^{\frac{1}{3}}$ \\
$\delta_{\text {min }}$ & $(80<\operatorname{Re}<900)$ & $\delta_{\min }{ }^{+}=0.935 R e^{0.24}$ & $\delta_{\min }=1.094 R e^{0.16}\left(\frac{v^{2}}{g \sin \varnothing}\right)^{\frac{1}{3}}$ \\
$\delta_{\max }$ & $(200<\operatorname{Re}<900)$ & $\delta_{\max }{ }^{+}=0.0033 R e^{1.5882}$ & $\delta_{\max }=0.0254 R e^{1.059}\left(\frac{v^{2}}{g \sin \varnothing}\right)^{\frac{1}{3}}$ \\
$\delta_{\text {sub }}$ & $(80<\operatorname{Re}<850)$ & $\delta_{\text {sub }}{ }^{+}=0.455 R e^{0.437}$ & $\delta_{\text {sub }}=0.677 R e^{0.29}\left(\frac{v^{2}}{g \sin \varnothing}\right)^{\frac{1}{3}}$ \\
\hline
\end{tabular}

$\delta_{p}$ and $\mathrm{U}_{\text {wave }}$ are of great importance to describe the nature of solitary waves on film flow. This paper also processes the test data in dimensionless form to obtain empirical correlations for these two parameters.

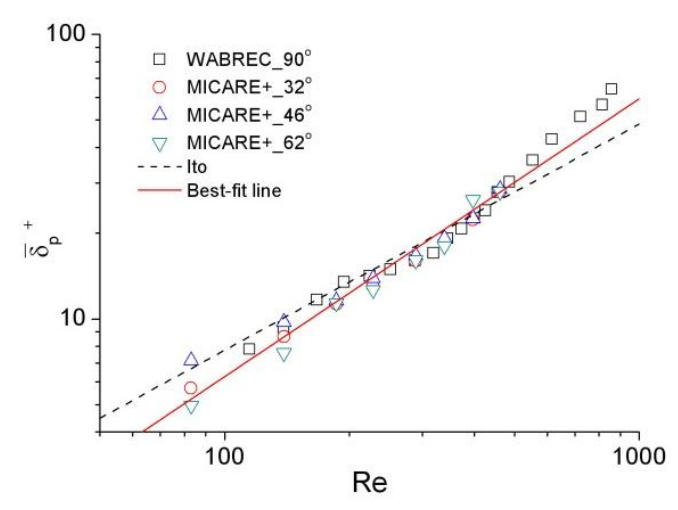

(a) $\delta_{p}{ }^{+}$

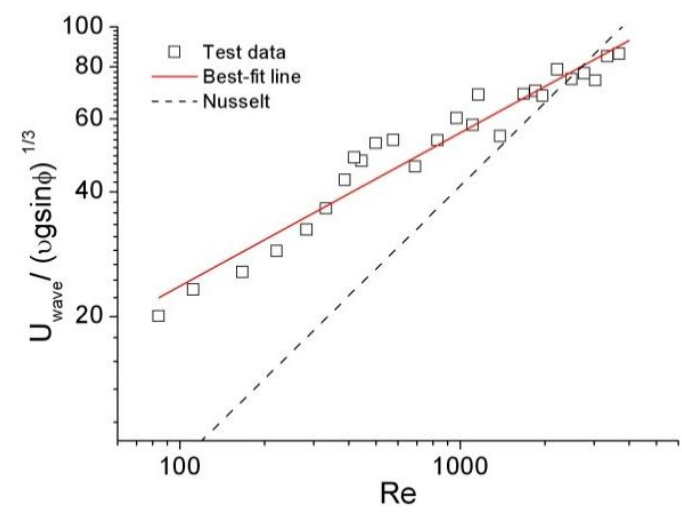

(b) $\mathrm{U}_{\text {wave }}{ }^{+}$

Fig. 15. Dimensionless parameters of surface wave

$\bar{\delta}_{p}^{+}$is processed with equation 17 in dimensionless form and plotted in figure15a. The wave velocity can be calculated according to Nusselt theory as follows:

After rearrangement:

$$
U_{\text {wave }}=U(\delta)=0.4127 R e^{2 / 3}(v g \sin \phi)^{1 / 3}
$$

$$
U_{\text {wave }}^{+}=\frac{U_{\text {wave }}}{(v g \sin \phi)^{1 / 3}}=0.4127 R e^{2 / 3}
$$

It can be seen that nondimensionalizing $U_{\text {wave }}$ with $(v \operatorname{gsin} \phi)^{1 / 3}$ is reasonable. The empirical correlations for solitary waves are obtained from least square method and listed in table 4 .

Table 4 Empirical Correlations for Solitary Wave

\begin{tabular}{cccc}
\hline Parameter & Range of Reynolds number & Dimensionless Empirical Correlation & Empirical Correlation \\
\hline$\overline{\delta_{p}}$ & $(80<\operatorname{Re}<900)$ & ${\overline{\delta_{p}}}^{+}=0.07 \operatorname{Re} e^{0.976}$ & $\overline{\delta_{p}}=0.194 \operatorname{Re} e^{0.651}\left(\frac{v^{2}}{g \sin \varnothing}\right)^{\frac{1}{3}}$ \\
\hline
\end{tabular}


$\mathrm{U}_{\text {wave }} \quad(80<\operatorname{Re}<3600)$

$U_{\text {wave }}^{+}=4.31 R e^{0.37}$

$U_{\text {wave }}=4.31 R e^{0.37}(v g \sin \phi)^{\frac{1}{3}}$

For free falling film flow, seven variables $\left(\mathrm{U}_{\text {wave }}, \rho, \mathrm{g}, \mathrm{v}, \Gamma, \lambda, \sigma\right)$ and three dimensions $(\mathrm{m}, \mathrm{s}, \mathrm{kg})$ are applied to describe the flow status. According Buckingham's (1981) $\pi$ theory, these seven variables can form four dimensionless groups:

$$
\begin{aligned}
& \Pi_{1}=\rho^{a 1} g^{b 1} v^{c 1} U_{\text {wave }} \\
& \Pi_{2}=\rho^{a 2} g^{b 2} v^{c 2} \lambda \\
& \Pi_{3}=\rho^{a 1} g^{b 1} v^{c 1} \Gamma \\
& \Pi_{4}=\rho^{a 1} g^{b 1} v^{c 1} \sigma
\end{aligned}
$$

Four dimensionless variables $U_{\text {wave }}{ }^{+}, \lambda^{+}$, Re, $\gamma$ are obtained through dimension analysis (table5).

Table 5 Dimensionless Group

\begin{tabular}{cccccc}
\hline Group number & \multicolumn{3}{c}{ Parameters } & Dimensionless expression & Dimensionless variable \\
\hline$\Pi_{1}$ & $a_{1}=0$ & $b_{1}=-1 / 3$ & $c_{1}=-1 / 3$ & $\Pi_{1}=U_{\text {wave }}(g v)^{-1 / 3}$ & $\mathrm{U}_{\text {wave }}{ }^{+}$ \\
$\Pi_{2}$ & $a_{2}=0$ & $b_{2}=1 / 3$ & $c_{2}=-2 / 3$ & $\Pi_{2}=\lambda /\left(v^{2} / g\right)^{1 / 3}$ & $\lambda^{+}$ \\
$\Pi_{3}$ & $a_{3}=-1$ & $b_{3}=0$ & $c_{3}=-1$ & $\Pi_{3}=\Gamma / \mu$ & $\mathrm{Re}$ \\
$\Pi_{4}$ & $a_{4}=-1$ & $b_{4}=-1 / 3$ & $c_{4}=-4 / 3$ & $\Pi_{4}=\sigma / \rho v^{4 / 3} g^{1 / 3}$ & $\gamma$ \\
\hline
\end{tabular}

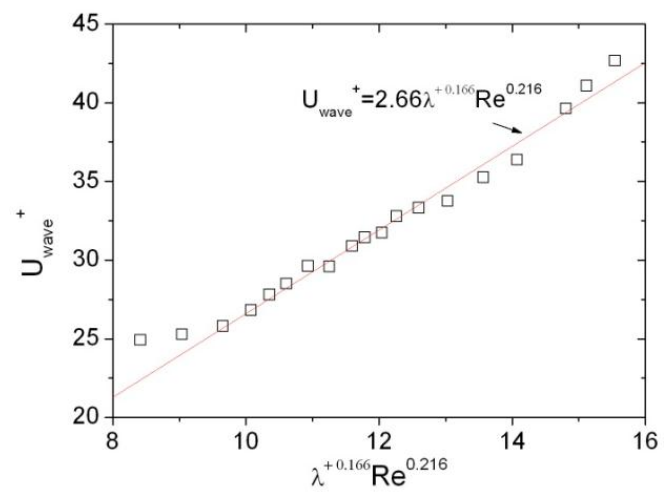

Fig. 16. Relationship between dimensionless wave length、 velocity and Reynolds number

The property of the film flow in this paper does not change. As a result, $\gamma$ almost keeps constant. Nakoryakov's et al., (1976) study suggested that $U_{\text {wave }}{ }^{+}$is proportional to $\gamma^{\mathrm{a}} \lambda^{\mathrm{b}} \mathrm{Re}^{\mathrm{c}}$. But rare data is available to prove this relationship and obtain the exact value of coefficients $\mathrm{a}, \mathrm{b}$ and $\mathrm{c}$. Based on the experimental data in this paper, multiple linear regression analysis is applied to obtain the empirical relation between $\mathrm{U}_{\text {wave }}{ }^{+}, \lambda$ and Re. Figure 16 shows good linear relation between $U_{\text {wave }}{ }^{+}$and $\lambda^{+0.166} \mathrm{Re}^{0.216}$.

\section{Conclusion}

This paper described a film flow experimental study on a large vertical and an inclined flat plate with a wide range of Reynolds number (50 to 3600). Statistical characteristics of film thickness and solitary waves are analyzed to obtain better understanding of the mechanisms of film flow. The effects of Reynolds number and inclination on film flow are also investigated. The main conclusions are summarized as follows: 
1) There exist three clear transition points within the Reynolds number range in this study. The first one indicates that the pattern of the solitary wave becomes self-locking, which suggests that the wave height and wave length begin to be almost invariant. The second one indicates the appearance of heap waves that carry large amounts of mass and energy with complex surface structure. The third transition point indicates that the film flow turns from semi-turbulent to fully turbulent.

2) In general, the solitary waves of film flow develop from low speed waves of high frequency and short wave length to high speed waves of low frequency and long wave length with increase of Reynolds number.

3) The authors hypothesize that there exists a transition point related to the plate inclination. This transition point may indicate that the gravity begins to influence the film flow in a different way.

4) Empirical correlations of $\bar{\delta}, \delta_{\min }, \delta_{\max }, \delta_{\text {sub }}, \delta_{\mathrm{p}}, \mathrm{U}_{\text {wave }}$ of film flow on large flat plate are obtained. It could be applied to the safety analysis program for nuclear power plant, such as GOTHIC and WGOTHIC.

5) The relationship between $\mathrm{U}_{\text {wave }}{ }^{+}, \lambda^{+}$, Re of film flow on large flat plate is obtained.

\section{Acknowledgements}

The support from China National Key Projects 2010ZX06002-005 is gratefully acknowledged. This work is also supported by the U.S. Department of Energy, Basic Energy Sciences, Office of Science, under contract \# DE-AC02-06CH11357.

\section{References}

Jiang Z.,Yan W., Tao Z., Experimental Studies on Heat Transfer to Non-Newtonian Power-law Fluid Falling Film Flow [C]. Proceeding of the International Symposium on Multiphase Flow, Edited by Chen X., Ge M., International Academic Publishers, Beijing, 1997, 356-361

Takamasa T., Hazuku T., Measuring Interfacial Waves on Film Flowing down a Vertical Plate Wall in the Entry Region Using Laser Focus Displacement Meters [J]. International Journal of Heat and Mass Transfer, 2000, 43(15): 2807-2819

Nosoko T., Yoshimura P.N., et al., Characteristics of Two-dimensional Waves on a Falling Liquid Film [J]. Chemical Engineering Science, 1996, 51:725

Yoshimura P.N., Nosoko T., Nagata T., Enhancement of Mass Transfer into a Falling Laminar Liquid Film by Two-dimensional Surface Waves-Some Experimental Observations and Modeling [J]. Chemical Engineering Science, 1996, 51(8):1231-1240

Philipp A., Ulrich R., Hydrodynamics of Three-dimensional Waves in Laminar Falling Films [J]. International Journal of Multiphase Flow, 2000, 26(7):1183-1208

Sutalo I.D., Bui A., Rudman M., The Flow of Non-Newtonian Fluids down Inclines [J]. Journal of Non-newtonian Fluid Mechanics, 2006, 136:64-75

Moran K., Inumaru J., Kawaji M., Instantaneous Hydrodynamics of a Laminar Wavy Liquid Film [J]. International Journal of Multiphase Flow, 2002, 28:731-755

Xu Y.Y, CFD Simulation and Validation to Portray the Liquid Flow Behavior for Multiphase Flow [D]. Shanghai Jiao Tong University, 2010

Tihon J., Serifi K., Argyriadi K., Bontozoglou V., Solitary Waves on Inclined Films: Their Characteristics and the Effects on Wall Shear Stress [J]. Experiments in Fluids, 2006, 41(1):79-89

Ambrosini W., Forgione N., Oriolo F., Statistical Characteristics of a Water Film Falling Down a Flat Plate at Different Inclinations and Temperatures [J]. International Journal of Multiphase Flow, 2002, 28:521

Nusselt N, Die Oberflachenkondensation des Wasserdampfes [J]. Zeit.Ver.D.Ing, 1916, 60:541-569

Takahama H., Kato S., Longitudinal Flow Characteristics of Vertically Falling Liquid Films without Concurrent Gas Flow [J]. International Journal of Multiphase Flow, 1980, 6(2):203-215

Telles A.S., Dukler A.E., Statistical Characteristics of Thin, Vertical, Wavy, Liquid Films [J].Industrial \& Engineering Chemistry Fundamentals, 1970, 9(3):412-421

Chang H.C., Evolution of Nonlinear Waves on Vertically Falling Films-A Normal Form Analysis [J]. Chemical Engineering Science, $1987,42: 515-533$ 
Yu Y.Q., Wei S.J., Yang Y.H., Cheng X., Experimental study of water film falling and spreading on a large vertical plate [J], Progress in Nuclear Energy, 2012, 54:22-28

Yu Y.Q., Yang Y.H., Cheng X., Gu H.Y., Numerical simulation on falling film behavior [J], Atomic Energy Science and Technology, 2012, 46(10):1207-1211

Yu Y.Q., Gu H.Y., Cheng X., Numerical simulation on heat-transfer character of subcooled falling film on flat plate, Atomic Energy Science and Technology, 2013, 47(1):48-53

Karapantsios T.D., Paras S.V., Karabelas A.J., Statistical Characteristics of Free Falling Films at High Reynolds Numbers [J]. International Journal of Multiphase Flow, 1989, 15(1):1-21.

Ito M.S., Breakdown and Formation of a Liquid Film Flowing down an Inclined Plane [J], Transaction of the Japan Society of Mechanical Engineers, 1986, 52 (475B):1261-1265

Karapantsios T.D., Karabelas A.J., Longitudinal characteristics of wave falling films [J]. International Journal of Multiphase Flow, 1995, 21:119-127

Mori K., Matsumoto T., Uematsu H., Time-spatial Interfacial Structures and Flow Characteristics in Falling Liquid Films [C]. In: Third International Conference on Multiphase Flow, ICMF'98, Lyon, France, June 8-12, 1998

Leuthner S., Maun A.H., Auracher H., A High Frequency Impedance Probe for Wave Structure Identification of falling films [C]. In: Third International Conference on Multiphase Flow, ICMF'98, Lyon, France, June 8-12, 1998

Takamasa T., Tamura S., Kobayashi K., Interfacial Waves on a Film Flowing Down Plate Wall in an Entry Region Measured with Laser Focus Displacement Meters [C]. In: Third International Conference on Multiphase Flow, ICMF'98, Lyon, France, June 8-12, 1998.

Kapitza P.L., Wave Flow of Thin Layers of Viscous Fluid [J], Collected Papers of P.L. Kapitza, 1964, 2:662-713

Levich V.G., in: Physiochemical Hydrodynamics [C], Prentice-Hall, Englewood Cliffs, NJ, 1962, 683-693

Lienhard J.H., A Heat Transfer Textbook [M], Prentice-Hall, Englewood Cliffs, NJ, 1981:113-119

Nakoryakov V.E., Pokusaev B.G., Alekseenko S.V., Stationary Two-dimensional Rolling Waves on a Vertical Film of Liquid [J]. Journal of Engineering Physics and Thermophysics, 1976, 30:517-521

Qiu Z.F., Xie Z.R., Gu H.Y., Cheng X., Experimental and Numerical Studies on Mixed Convection in Vertical Rectangular Channels [J].Nuclear Power Engineering, 2009,30(6):12-17

Hajmohammadi .M.R., Nourazar S.S., On the solution of characteristic value problems arising in linear stability analysis; semi analytical approach [J]. Applied Mathematics and Computation, 2014(a), 239:126-132

Hajmohammadi .M.R., Nourazar S.S., Campo A., Analytical solution for two-phase flow between two rotating cylinders filled with power law liquid and a micro layer of gas [J]. Journal of Mechanical Science and Technology, 2014(b), 28(5):1849-1854

Hajmohammadi .M.R., Nourazar S.S.,On the insertion of a thin gas layer in micro cylindrical Couette flows involving power-law liquids [J]. International Journal of Heat and Mass Transfer, 2014(c), 75:97-108

Brissinger D., Parent G., Boulet P., Experimental study on radiation attenuation by a water film [J]. Journal of Quantitative Spectroscopy and Radiative Transfer, 2014, 145:160-168.

Wang T., Faria D., Stevens L.J., Tan J.S.C., Davidson, J.F., Wilson D.I., Flow patterns and draining films created by horizontal and inclined coherent water jets impinging on vertical walls [J]. Chemical Engineering Science, 2013, 102:585-601

Gondaa A., Lancereaua P., Bandeliera P., Luoc L., Fanc Y., Benezechd S., Water falling film evaporation on a corrugated plate [J] , 2014, 81:29-37 